\title{
A Multimodal Discourse Analysis of a Yoruba Song-drama
}

\author{
Olateju Moji. A \\ Correspondence: Olateju Moji. A, Department of English, Obafemi Awolowo University, Ile-Ife, Nigeria
}

Received: May 29, 2015 Accepted: June 10, $2015 \quad$ Online Published: July 6, 2015

doi:10.11114/jets.v3i5.933

URL:http://dx.doi.org/10.11114/jets.v3i5.933

\begin{abstract}
This paper presents a multimodal discourse analysis of a story that has been turned into a Yoruba song-drama, highlighting the ideational, interpersonal and textual aspects of the song-drama. The data is a short song-drama meant to teach children importunity, determination and hard work through persistence. The multimodal and narrative conventions used for analysis according to Kress and van Leeuwen (2001), show the need for cooperation and determination in a world that is characterized by individualism. The study reveals that, at the ideational level, information, anticipation, request and insistence are prominent features. At the interpersonal level, the study reveals that the song-drama is a metaphor for the possibility of a better life for the poor and needy in a society full of oppression and selfishness, while the textual level reveals the distribution of information in the different modes- song, drama, and paralinguistic expressions. The study concludes that pedagogically, storytelling, re-telling, writing and rewriting have the capacity to improve pupils' vocabulary development. ESL teachers could creatively use video watching (which has replaced story telling), storytelling and retelling to launch the present day ESL learners into $21^{\text {st }}$ century critical thinking and learning activities.
\end{abstract}

Keywords: ideational, multimodality, textual, interpersonal, song-drama

\section{Introduction}

Toolan (1996) defines a narrative as a text in which something humanly interesting has happened, or a significant change in the situation has occurred. He sees human communication as highly multimodal and that stories that are accompanied with songs, dance etc are multimodal while oral tales, short stories etc that are unaccompanied are mono modal. In most African contexts however, oral tales and storytelling are usually accompanied with songs such as call and response, solo, group response, locally made musical instruments, clapping etc.

Amana and Omale (2015) note that in traditional African setting, folklore and stories are a primary means of building characters as well as developing verbal dexterity and mental activity in children. Songs and dances accompany story telling in traditional African or Nigerian societies where acceptable morals and communal living are taught.

Africans, and in particular Nigerians, have not stopped telling stories. Stories are now being told through screen plays in form of home videos and through comedians in specialized social gatherings. Unlike the traditional/home settings where you do not have to pay to listen to stories, video films have to be bought and gate fees in most cases have to be paid to listen to most comedians.

\subsection{The Yoruba People}

The Yoruba people occupy the Southwestern part of Nigeria. They are very industrious, religious and they have a lot of cultural and social values. Their language is a tonal language which they use creatively in every area of their lives. They have all kinds of songs and greetings for different occasions. The Yoruba people believe in the communal training of children and everybody sees it as a community service. It may be one concept or lesson that a story is meant to teach but by the time other modes such as music, dance, costumes etc, are added, the story ends up teaching more than the intended concept. The modes in contemporary times end up transporting ideas from ordinary stories to social values sometimes by crossing local or religious barriers and boundaries and presenting them as human values for all ages and times. This is what has happened in the text under consideration in this paper.

\section{Theoretical Base}

\subsection{Multimodality in Communication}

Mono modality which means using only one mode in expressing ideas in writings, literary works, art forms, Marlene 
Schommer-Aikinsperformances etc, which was highly valued in the past has given way to multimodality (using different modes to express oneself in writing, literary works, performances etc). Kress and van Leeuwen (2001) note for example, that, in western cultures, the preference for oil paintings has reduced and some old art works are now confined to museums and galleries for record purposes and posterity. In Nigeria for example, in religious circles, classical music and hymns (which were purely mono modal) are gradually giving way to choruses, choreography, artistic dances which are multimodal in the sense that they are accompanied with all kinds of colors, styles of costumes, lyrics, movements, artistic displays etc. Going through some media resources such as magazines, news papers, photographs, committee rooms of corporations, institutions, display of menu lists at eateries, directions at bus stops etc, reveals that these resources have taken a new multimodal outlook and some of the compositions can not be glossed over because of their attractive and appealing nature. In defense of multimodality, Kress and van Leeuwen $(2001,01)$ note the following:

The desire for crossing boundaries inspired twentieth century semiotics. The main schools of semiotics all sought to develop a theoretical framework applicable to all semiotic modes, from folk costume to poetry, from traffic signs to classical music, from fashion to the theatre ------ In our own work on visual semiotics (Kress and van Leeuwen 1996), we too were in a sense 'specialists' of the image, still standing with one foot in the world of monomodal disciplines. But at the same time we aimed at a common terminology for all semiotic modes and stressed that within a given socio-cultural domain, the 'same' meaning can often be expressed in different semiotic modes.

In support of the above claim by Kress and van Leeuwen (2001), Olateju and Oyebode (2014) note that:

Discourse analysis has gone beyond ordinary analysis of any written or spoken text. It has extended its tentacles to all other modes of communication which of course now gives readers or researchers a wider scope to operate in the enterprise of interpreting and analyzing any form of text in arriving at a robust meaning or the intended message.

Meaning is therefore made in any form of communication in different ways. It could be through the linguistic elements or the visuals. It could also be through different modes or media in an ensemble. The study of meaning in communication has grown beyond the traditional idea that meaning resides only in written language or that written language is the central thing in meaning. There are other extra- linguistic and paralinguistic resources in any form of communication. All these other modes have always been there but have not really been spoken about until scholars such as Gunther Kress, van Leeuwen, Jay Lemke, David Machin and some others started writing about them.

Kress and van Leeuwen (2001) explain these multimodal layers of meaning by sketching a multimodal theory of communication which concentrates on two things: 1. the semiotic resources of communication and 2. the communicative practices in which these resources are used. These communicative practices are presented as multilayered and they involve discursive practices, production practices and interpretive practices, design practices and distribution practices. Kress and van Leeuwen (2001) note that, meaning is made at different places within each of these communicative practices and that whenever a culture decides to introduce a particular material into its communicative practices or processes, that material becomes part of the cultural and semiotic resources of that culture for making signs.

\subsection{Communicative Practice}

This has to do with representation and interaction in any communicative ensemble. When we communicate, we interact with people. It could be a form of entertainment through story telling, arguments, debates, or through a written expression. We also communicate through visuals or visual representation of ideas, motives and intentions. No communication can exist without some form of representation. The representation may not be physically seen, it maybe mental at times. Kress and van Leeuwen (2001) see representation in terms of social practice which involves discourses, design, production and distribution. They define discourse as knowledge of practices of how things are done or must be done. Discourses can be realized by a range of semiotic resources (colors, words, pictures etc) and communicative practices. As regards the design, they could be told orally, written, made into a film etc. Kress and van Leeuwen note that the design complements the discourse by getting contextualized, and these may include, giving parental advice, telling a story, advertising a product etc. The production could also take different forms. It could be sketched for a kindergarten class to identify and paint, a word or picture puzzle could be created for a higher class, it could also be story telling for another etc. The distribution aspect of it has to do with how the text becomes the possessions of readers and viewers.

\subsection{Semiotic Resources}

Semiotic resources can be in different forms, for different cultures, groups of people etc. For example, languages are resources for their speakers. The Yoruba language is a resource for the Yoruba people. Books of different kinds, the internet, libraries, etc are resources where different kinds of people could shop for ideas, language items, designs etc. 
Literary traditions of community members are resources to the members which could be used for creative purposes any time.

Kress and van Leeuwen (2001) however note that no semiotic resource is either by nature lexical or grammatically organized, but once a mode is grammaticalised, it will acquire some high valued peculiarities and facilities such as the ability to produce recognizable signs. Halliday (1978) notes that semiotic resources are system(s) of meanings through which the cultural practices of a community can be read or understood. Visual grammar is gradually appearing through the works of scholars such as Gunther Kress and van Leeuwen, Jay Lemke, David Machin etc and it is fast gaining grounds in modern communication. O'Halloran (2008) notes that, the strength of MDA (Multimodal Discourse Analysis) is Halliday's 1978/2004 metafunctional principles of ideational, interpersonal and textual functions in the sense that, they create a platform for creating meaning. These principles will also be used in the analysis of the data for this paper. Some other notable scholars who have worked on different texts using multimodal principles are: O'Halloran (2002/2008), Unsworth and Cleirigh (2009), O'Toole (1994/2010), Martinec (2005), Machin (2009), Lemke (2002), Jewitt (2009) etc.

\section{The Data}

The text for this paper which is a Yoruba song-drama was originally designed to teach 'importunity' in a children's Sunday school class. The synopsis of the text reveals that a blind man cried for help when he heard that a superman who could help him was passing by. The crowd tried to discourage him by saying that the superman was no longer around. But the blind man kept on shouting for help until the superman heard and asked that the blind man be brought to him. The superman asked the blind man what he wanted and the blind man said he wanted his sight back. He got his sight back and demonstrated his joy by singing, dancing and jumping up in the presence of the crowd. His jubilation is a practical narration/demonstration of activities he had longed for. The story has therefore moved from the realm of a written bible story (purely mono modal) to a multimodal one that has added modes for representation and extension of meaning for social purposes and for learning. Some of the modes represented in the song-drama are universal. For example, almost every culture has one type of music, or dance for different occasions and situations. Given the social and cultural history of the modes represented in the song-drama, the affordances of these modes could therefore be expected to be generally understood as a lively accompaniment to a story which has changed its status to that of a song-drama.

In this essay therefore, we hope to be able to, through this multimodal approach to communication, highlight some socio-cultural values embedded in the story, and also extend understanding of the song-drama in relation to the world around us through the representation of the different modes used in the text. Jewitt and Kress $(2003,9)$ note that;

people use resources that are available to them in the specific socio-cultural environment in which they act to create signs, and in using them they change these resources

It is therefore important to note that, despite the religious allusion to a bible story in the text, through the lyrics, the story has been given a traditional Yoruba setting that has situated the story on the Nigerian soil and in particular, the Yoruba land.

Machin (2010) notes that a basic discourse schema or activity is useful in revealing the social values that underlie a narrative. The discourse reveals in a simple way, what happens in the song, what the story is all about etc. Presenting the discourse schema could reveal the cultural values being communicated. Machin $(2010,78)$ commenting on the earlier submissions of some earlier scholars on discourse schema notes further that:

Social anthropologists and social psychologists have shown that while the kinds of stories, myths, folk tales may show animals creatures travelling across fantastic lands and being involved in adventures, at their roots are very basic messages about the kinds of values and identities cherished by a particular culture, about the concerns and worries and boundaries.

Wright $(1975,12)$ corroborates the views above by arguing that stories

can enable us to achieve a greater understanding both of the mind's resources for conceiving and acting in the world and of the organizing principles and conflicting assumptions with which a specific society attempts to order and cope with its experience

The text in this paper has a story that belongs to the genre of biblical/historical story. The story has a discursive move of human beings' inquisitive nature of seeking supernatural solution to physical problems. There are three interrelated discourses at work here, that of the powerful man with the metaphysical power, the inquisitive crowd not mindful of a blind man's predicament; the discouragement from the crowd and their insensitivity to the blind man's problem; and the bold cry and struggle for help by the blind man- a metaphor for a world that is insensitive to some basic human problems. The song drama is also a metaphor for the poor or incapacitated in a seemingly insensitive world. The story 
also demonstrates the readiness of a caring philanthropist to help a blind man (who represents the common man).

The story is situated in an historical/biblical past when advancement in western medicine was still limited and good medical care was not within the reach of the common man. Up till now, it is still not within the reach of the common man in some developing nations of the world. The blind man sits everyday by the road side begging for alms from passers-by. He is not economically empowered enough to seek medical attention and therefore depends on other people for assistance. The story could also be situated in a modern society especially in poor countries where blind people still roam the streets for alms.

The story could be said to move from history to religion and then to socio economic/social problems. It is history because it is from a story of an event recorded to have happened in a distant past. It is a religious discourse because it has its origin in the bible and because of the metaphysical power demonstrated in favor of a blind person. It is social because it involves happenings in the society that have to do with the poor, dejected, outcast, underprivileged and marginalized lower class, the privileged rich and powerful and the crowd. It is socio-economic because of lack of financial empowerment of the blind man and the dependence on community members for survival. It is a situation that is still physically present in some human societies today.

There is class distinction- the powerful versus/ the less powerful/underprivileged. The historical record of clothes worn at that time shows the figure of the powerful man in white flowing garment, with other people in flowing garments following him for different reasons- curiosity, help (physical/spiritual), money, support, healing, report, witness. The solemnity of religious preaching, words and promise of a world without end is noticed in the song drama. The discourse here represents a set of beliefs in a powerful personality that can deliver from oppression.

For the religious minded people, there is the picture of an extraordinarily powerful person who is mindful of the underprivileged. For the socialist, it is the picture of an oppressive society where there is an uneven distribution of social/economic resources, opportunities and privileges. It is a society that is less mindful of the poor and would prefer shouting the poor man/person down rather than helping him/her. For the modern and the educated man, there is a ray of hope for the poor (who represent the society). Attention is given to the underprivileged and there is the joy of being free from disability or any form of physical or economic oppression.

\subsection{Participants in the Song Drama}

\subsubsection{The Powerful Man}

The powerful man is presented as a, rich, wealthy, honorable and powerful liberator who controls a lot of resources. This is revealed in his lyrics and invitation to all and sundry. Some of the ideas expressed and manifested through the use of lexical items by the super man are;

olà -wealth

olá- honour

The superman keeps emphasizing wealth, riches and honor in his lyrics. He is wealthy and he encourages people to renounce the simple/directionless way of life, come out of poverty and aspire to a better and edifying state of existence. $\mathrm{He}$ is also honorable, lives in a honorable place and invites the populace to that place of honor. He notes in his song that the key to the good, comfortable and honorable life is by being kind hearted and abstaining from all forms of wicked practices. Despite the fact that the crowd is privileged to follow and listen to the superman, the blind man is not considered relevant or good enough to partake of the good way of life or the benefits of the good place that the powerful man advocates. The powerful man demonstrates this goodness by providing food and health care services for the populace and imagines a society where the good life is within the reach of everyone. The superman, like the modern day politician, moves from city to city calling for the good life and asking them to join his campaign team for the good life for both old and young.

\subsubsection{The Blind Man}

Generally and especially in Africa, a blind man is not a free man. He is bound and limited by the absence of sight. His movement is restricted and except assisted, he is helpless. He has no choice as to what to wear, eat, drink or choose his mode of relaxation. He has no resources to plan for holiday or go for one. He has to keep begging until he ceases to exist. What he is offered are left over of unneeded or useless clothes and left over change in terms of money. The beggar is not assisted so that he can change his status from being a beggar to a house owner but just to keep body and soul together. Just as mentioned earlier, the blind man/person could be seen as a metaphor for the underprivileged in a society that is always at the mercy of the rich.

\subsubsection{The Crowd}

This is a common phenomenon in all societies. They can cooperate to do well or do otherwise. Many just follow what 
others do or say. They have no mind of their own. The crowd could be very undecided and irrational. A typical common crowd is inquisitive, selfish, and lover of free things. This is evident in their songs and responses to the superman's invitation and the blind man's call for assistance.

$$
\begin{aligned}
& \text { Ká wa lè wolé olá - that we may enter the honorable house } \\
& \text { Ká wa lè wolé olà - that we may inherit a wealthy place } \\
& \text { Paradise lokè -beautiful honorable place }
\end{aligned}
$$

The response of the crowd only covers the honorable and expected good life, not how to work for it. The crowd displays their lack of compassion by giving incorrect information and shouting the blind man down, telling him that the superman has gone to another city. The superman proves them wrong by immediately demanding that the blind man be brought to him. To the superman, his concept of the inheritance of a wealthy place is a psychological one which is reflected in the physical through healthy living and availability of the essentials of life.

\section{Discussion}

\subsection{Design}

The text for this paper is a combination of song, drama, and language. There is a song, movement to the rhythm of the song and the wordings of the song. Sound (music and the words) and image are made to enact or create language in action in the musical drama. Burn and Parker's (2003) work on the moving image on the screen note that a moving image is an assemblage of modes which have drawn a lot of attention throughout its history. Their observation is relevant to this work because the data used also involves rhythm and humans moving to the rhythm of the music even though it is not on the screen. The moving images (several) in the text for this work represent different social groups. The crowd represents people or images of different social groups, ages, community members and/or probably nations. The semiotic resources are those needed for the creation of a crowd since they are different kinds of people. These resources are:

1. the image of a blind beggar in dirty old clothes by the road side;

2. different colours of attires for the different classes of people represented by the crowd;

3. white flowing attire for the superman; and

4. a walking stick for the blind man.

The production of the images in a musical drama could help pupils in the design of various resources for the different stages of a musical drama. Designing and representing time, speed and direction in a text of this type is very important in critical thinking process. If this musical story is placed on a story board representing visual space, the blind man will be presented first, as a wretched beggar, neglected and oppressed by the crowd by the road side. Next, is the beggar going to the superman, the dialogue between the beggar and the superman and last is the beggar's demonstration of his happy state of mind on sight recovery. The positioning of the arms and legs, the elated eyelids, open mouth, frantic jumps into the air and an imaginary table on which he puts his legs in demonstration of his freedom from disability are all part of the design. These different representations of the design then become a part of the resources for meaning-making in the piece. If these images are recorded and scanned, they then become digital resources for animation into a computer software package.

\subsection{Ideational Function}

The ideational level according to Halliday (2004) has to do partly with participant identification and construction. The question that must be asked here is who is doing what? The answer rests on three sets of people. Two out of whom are individuals and the last a group. The story cannot be said to have a clear cut narrator because each person or the group comes in at different times to song-play their parts. The blind man hears the solemn invitation to the right kind of life by the superman and gets interested. The movement and sound of many people passing by attracts his attention and then calls for help from the super man. The superman's ability to hear the voice of a blind man above that of a crowd also shows part of his natural ability to detect a distressed voice in the midst of noise or confusion. The following are evident in the musical drama.

- The crowd tries to discourage or dissuade the blind man from getting help (this is a common feature of oppression in any society).

- The crowd insists that the superman has gone to another city.

- The blind man refuses to be discouraged by the crowd but keeps on calling the name of the superman.

- Despite the harsh tone of the crowd the blind man keeps shouting. 
- $\quad$ The superman attends to the blind man but not wanting to take anything for granted; he first asks what the blind man wants because it could be money.

At the ideational level, the discourse shows information, anticipation, request, insistence and assistance, which leads to a success story.

Time is used to condense a series of narrative events that could have occurred for a longer time in rapid succession. Actions are used to depict the passage of story time as the blind man goes to the superman and stands before him waiting for his response. Singing is also used to depict the passage of story time because some of the actions or steps in the act do not get enacted until the song is over while some others actually take place in the musical drama while the singing is on. An example is that of the blind man jumping, leaping and singing for joy all at the same time as he expresses his joy at the restoration of his sight. Ideationally, we see the willingness of the superman to help the blind man which is demonstrated by his request to have the blind man brought to him. Secondly, we note the demonstration of the metaphysical power without any physical act of touching the blind man, meaning all is not lost for the poor, needy or destitute.

It is to be noted here that what happens here is opposed to western medical practice or orthodox medicine or trado-medical practice where physical contact is important in terms of physical examination, history taking, test reports etc. Some may also compare the restoration of the blind man's sight to metaphysics (without material form or substance, highly abstract), where a patient does not have any application of drugs yet gets better through interaction with the necessary medical personnel.

\subsection{Representation}

The musical drama tells the story. It is a marriage of music with drama or action. Words are spoken in rhythm with moving images in form of human beings. Melody is accompanied by all the necessary pauses. The repetitive pattern of the song gives room for emphasis and time lapse between one step of the act and the other. The only act is the healing of the blind man. The opening section of the lyrics of the superman is just a flashback to previous actions of the superman. Different levels of modality are also represented in the song-drama. Below are some of them. There are representations of certainty and uncertainty in the lyrics of the song. Examples are given below;

Crowd

Batimeu pánú rè mo o (2ce) high modality (certainty) and air of finality and denial

Jesu tí re kó já lo(2ce)

Jesu ti re kó já lo si ìlú mí i ràn

Batimeu, stop talking (2ce)

The superman has gone (2ce)

The superman has gone to another city

Blind man

Jéésù omo Dáfídì sà á nú fún mi medium modality (uncertainty) in terms of a request that the speaker is not sure would be granted

Superman, son of David, have mercy on me

The viewer, listener or reader has to do some mind processing to be able to account for the gap or pause in the song drama at any point in time. Kress and van Leeuwen (2001) mention or propose conventions that spectators learn and will construct as part of the process of internal sign production. The temporal construct as used by Kress and van Leeuwen (2001) span over three periods- for example, the past, in terms of the past activities of the super man, the past state of the blind man (wretched and poor) and the present demonstration of the metaphysical power to bring sight back to the blind man as demonstrated in the song drama below:

Máá lo o dìgbà (2ce)

ìgbàgbò o re mu o láradá o Batimeu (2ce)

Go, it's bye for now (2ce)

your faith has made you whole Batimeus (2ce)

The future is represented in the continuation of the good works of the superman and also in the future activities that the blind man notes in his song. This is indicated in the part of the song below. In this song, the future and the present also meet in that, he is performing the actions as the melody goes on. 
Ma a gbésè kan lé e rí

Ma á ma á jó roin roin

Ma a gbesè kan ròo kè láa la

Ma á ma á jó roin roin

Ma té tábìlì, ma je ma mu
I will lift up one of my legs very high

I will dance in circles

I will raise one leg up, up in joy

I will dance in circles

I will set a table, I will eat and drink

Ma da gèré omi só fun gè rè rè I will gulp down water in a fast manner

Ma a gbesè kan ròo kè láa la, I will raise one leg up, up in joy

Ma á ma á jó roin roin I will dance in circles

The song-drama of the blind man here expresses his joy at the recovery of his sight and therefore dances to highlight the things to do now and henceforth. For example, lifting up his legs to high heavens which he could not do before even when he was assisted or piloted; dancing in circles which someone who even has eyes has to be careful doing so as not to fall down; setting a table and drinking with joy etc. Some of the things he mentions here are things for which he had earlier received assistance. Raising up of legs in moments of joy generally is indicative of an internal 'self' satisfaction especially when 'self' has accomplished or acquired a great thing.

\subsection{Interpersonal Function}

This song drama is designed to encourage the listener/reader that no matter how terrible a situation is, solution can come from anyone and anybody. At the societal level it means-

- $\quad$ there is hope for the common man

- there is hope for the underprivileged

- $\quad$ there is need to turn deaf ears to all forms of discouragement

- those discouraging other people could turn around to be helpers

- $\quad$ there is no end to happiness or joy when suffering and affliction disappears

- the society becomes a better place when everyone is fulfilled

When staged, the actions, facial expressions of the characters would actually bring the theme of importunity alive and real in the minds of the viewers. Some of the things to take note of at the interpersonal level are: the proximity of the singers, the sad condition of the blind beggar, and the willingness of the superman to help the disabled, underprivileged and helpless in a society characterized by busy schedules, impatience and lack of concern for each other and especially the underprivileged. As noted earlier, the mode of a musical dialogue laden with action is juxtaposed to present a drama piece that has a lot of multimodal, social, cultural and pedagogical implications. Unlike pictures in books, animated objects, scanned images or pictures which may give readers, listeners or viewers different kinds of distance in terms of spatial principles or positioning, the spectators in a musical dialogue or drama usually find themselves participating emotionally in the drama. They see participants in the actual visual space performing and they can easily do a mental interpretation of participant identification, construction and the relationship between participants as they act or perform.

The superman is presented with a lot of people following him for help, attention, money, metaphysical demonstration of power, healing etc. The crowd is seen as a curious or anxious group looking for solution to whatever problems they have. The blind man is presented as a helpless man unable to cater for himself and always at the mercy of passers-by.

There are two protagonists in the short musical drama-the superman and the blind man. Both of them are at two extremes or ends of life. One is successful and powerful, the other hopeless and helpless. The meeting together of the two however brings first and foremost, fulfillment to the powerful, joy to the helpless and hopeless and the community, as the blind man no longer has to beg for daily living. The community members also do not have to be deprived of the material things they give or share with the blind man or the few coins they too could have used to take care of their family members.

\subsection{Textual Function}

This has to do with the distribution of information in the different modes- song, drama (action) and paralinguistic expression etc. In the opening dialogue-song of the superman, some words, phrases and sentences are repeated. i.e 'that we---'

$$
\begin{aligned}
& \text { káwa--that we--- } \\
& \text { káwa--- that we--- } \\
& \text { ké yin--- that you---- }
\end{aligned}
$$

Repetition can be said to be part of the features of the musical drama. It starts solemnly with a persuasive and grave 
tone because of the religious connotation that it has. Some of the words have their synonyms used.

$$
\begin{aligned}
& \text { 'ibi' -evil } \\
& \text { 'ikà'- wicked(ly) } \\
& \text { 'olá' -honor(able) place } \\
& \text { 'olà'- wealth(y)place } \\
& \text { 'rere'- good things } \\
& \text { 'ayò'- joyful things }
\end{aligned}
$$

'Ké yin'- that you (new information as at the point it is uttered) appears four times in thesong of the superman. 'Káwa''that we' in response to the superman's call to a higher social/economic and spiritual status is no longer new information in the response of the crowd. The inclusive 'we' is used to show that the crowd hears the clarion call of the superman to the good life he offers the crowd. Repetition does not mean acceptance here. It is just an acknowledgment of the information provided. The superman, the crowd and the blind man are all represented in the musical drama and identified by their contribution to the discourse. The crowd's discouraging response to the blind man's request is indicated with exclamation marks to show vigorous statements and commands.

$$
\begin{aligned}
& \text { Batimaeus shut up, Jesus has gone! } \\
& \text { Batimaeus shut up, Jesus has gone! } \\
& \text { Shut up! Shut up! } \\
& \text { Jesus has gone to another town!! }
\end{aligned}
$$

The air of finality with which their song ends could be taken as vigorous statements in the first, second and last lines and vigorous command in the third line. The last response of the superman in which he dismisses the blind man brings the solution to his problem. With open eyes, the blind man jumps up and starts singing. The crowd joins in the celebration. The information in the superman's text below is not direct but uttered in a metaphysical manner. For example, he says

\section{Go your way, bye for now}

Your obedience has you made you whole

The blind man comes for help only to discover that his obedience to the invitation of the superman has helped the process of healing his visual disability. He stands bewildered, not knowing what to do, experiences a temporary mental/visual pause and then a sequence of actions follow (checking his eyes, rubbing them, talking to himself, examining himself) etc. At last, he discovers he can see. He looks round, sees everyone around him, jumps up and starts shouting, expressing his joy at the restoration of his sight. The response of each group or individual marks the boundaries and groupings within the two modes as both are intertwined because one is used to enact the other. The songs are used to enact the actions. The participants do what the song says.

\subsection{Songs and Rhythm}

In this text, it can be said that the text is song and the song is the text. They cannot be separated. The story starts and ends with it. The story ends when the song ends. The songs separate the different segments of actions and the short story line. Time is compressed, delayed and responses to the actions are omitted in some parts. For example, in the first song, there is no evidence that people want to become inhabitants of the wealthy place that the superman sings about, that is, 'ilé olá'- the wealthy place/house.

The song of the blind man has a demonstrative rhythm as he reveals through his song the various things to do to show his appreciation. This multimodal analysis emphasizes the following: the music which itself is the text, the language of the text, the actions and demonstrative rhythms of participants in the musical drama. The color of the garment of the superman and his close followers is white. The crowd has different multicolored clothes. White could be said to signify openness and willingness and in religious discourse, purity which the superman demonstrates in the way he handles the case of the blind man while the various colors of the garments of the crowd symbolize a mixed multitude in terms of expectations, ideas, reactions, responses etc.

\section{Pedagogical Implications}

Storytelling and retelling (the village style) is an oral tradition that has been swept away by modernization, internet involvement and activities and the busy schedule of present day parents. Storytelling, story writing and listening to stories are social activities that have underlying language skills. These activities could translate to skills for good literary and linguistic performances both within and outside the classroom. Snell et al. $(2015,565)$ support this claim 
with the following;

Retelling supports vocabulary learning because, like rereading,

it increases children's exposure to new words

Snell et al. (2015) note further that even though retelling could boost children's vocabulary, it could also be cognitively demanding especially for young children. It is however academically rewarding in that, it increases children's exposure to and use of new words and concepts in a story. Lessons are learnt in telling and retelling stories. Morris (2015) in an article titled 'Preventing early reading failure' note the following contributions of Whitehurst and Lonigan (2001) in the following extract;

in the long run, time spent actively listening to

challenging stories is as important as time spent

reading simple stories in the reading circle

Morris $(2015,507)$

The above is in support of the underlining usefulness of storytelling or oral tales. We are usually influenced by what we hear, read or write about.

Some ESL teachers have complained about the poor standard of spoken/written English among public school pupils in Nigeria. Some of these language lapses have been revealed through students' work in both take-home and classroom oral contributions, assignments and writings. Scholars who have worked in this area include Aboderin (1980); Afolayan (1968); Asiyanbola (2003); Akande (2003); Olagoke (1975); Olateju (2006);Oluikpe (1974); Tomori (1963) etc. Most of the alternative activities that people engage in to replace story telling have however not translated into good writing and speaking skills especially in public schools. However, all hope is not lost (like the story of the blind man), as ESL teachers utilize these alternative activities creatively to develop pupils' language skills.

At the early stage of primary education, pupils should be encouraged to develop their creative and thinking abilities by drawing different characters in films or plays that they have watched (since watching films has taken over from storytelling). They could be asked to cut and paste these pictures on cardboards and then write under each picture. If carefully done, putting together the writings under each picture makes a complete story. This could even reveal students' innate abilities as regards some language skills. If pupils are asked to rewrite the story of the blind man used as text in this paper, they will come up with different interesting versions. Describing the actions of characters in a story helps pupils/students to develop their reporting abilities or skills. Summarizing the major events or land marks in a story teaches pupils economy of words. In other words, ESL teachers should

- create time for story-telling in the lower primary classes, and also encourage uninterrupted sustained silent reading (USSR) and report writing in the upper primary levels and secondary schools;

- encourage pupils to read more and then retell the stories they read in books and novels;

- encourage pupils to summarize what they have watched or read in their notebooks;

- allow pupils to act out interesting parts of a story;

- give allowance for story continuum (that is, a pupil starts retelling a story that most of the pupils have watched, he/she stops to allow another pupil to continue, this pupil also stops at a convenient spot to allow another pupil to finish telling the story. This will encourage attentiveness and participation in class);

- implore pupils to write the contributions of protagonists in the stories read;

- ask pupils to write down important and striking words and expressions in stories read; and

- encourage pupils to write their own stories by first writing about themselves.

Another thing that could help pupils is what Nash and Stancey (1980) refer to as textual intervention which was developed by the linguist critic and educator Rob Pope. According to Nash and Stancey (1980), textual intervention is

- a technique of participation;

- originally developed for literary analysis but not limited to literary analysis;

- good for analyzing different kinds of multimodal combinations of text and imagery;

- a good way of tricking a piece of writing into existence;

- a technique that gets you to play with the origins of an idea in such a way that you start a new writing without knowing it;

- a technique that does not only get you started but gets you going;

- interpretive and creative;

- a technique that makes you combine critical analysis with original insight; and

- a method for entering into texts by changing them. 
Nash and Stancey (1980) also note six steps in textual intervention which are well defined and intuitive and intended to generate new material out of old information. These are:

- making a change in the base text- that is, substitution of an entirely different point of view;

- describing the change that has occurred against the base text;

- describing the change using any vocabulary you choose. Creating texts offers you a good vocabulary for describing stylistic effect. You can ask questions such as who is doing what?

- discussing the differences in the change you have made. Does the change lead to a new situation?

- discuss your preferences; and

- list possibilities for further readings.

By the time you have taken these steps in writing, you have a newly created story or writing. In short, ESL teachers and learners could still have students' listening, speaking and writing skills developed despite all the societal distractions. After all, innovation and creativity are essential aspects of education.

\section{Conclusion}

In this paper, an attempt has been made to do a multimodal discourse analysis of a song-drama written in one of Nigeria's indigenous languages which is Yoruba. The song-drama tells the story. The distribution of information in the different modes- song, action and paralinguistics, all combine together for meaning-making and understanding of the text. The song-drama clearly reveals the need for the rich and powerful in positions of authority and power to be more attentive to the needs of the less privileged for the benefit of the society at large. The happy ending given the song drama is a metaphor for the possibility of a better life for the poor and needy in a world characterized by individualism.

Even though the song is meant to teach children certain virtues in life, pedagogically, it can be used to encourage children to think critically, construct technically and relate positively within a larger society apart from the world of the classroom or confines of a school building. The listening, speaking and writing skills of a child can be developed if ESL teachers channel the art of storytelling/ video watching, writing and re-writing positively to make writers, public speakers, creative and critical thinkers of the children they teach. This will help in bringing up a generation of individuals who will be democratic, good at conflict resolution and who will take positive steps for positive change in nation building.

\section{References}

Aboderin, A. O. (1980). Writing Skills in the Nigerian School Certificate English Language Programme, an unpublished Ph.D Thesis, Florida State University.

Afolayan, A. (1968). The linguistic Problems of Yoruba Learners and Users of English, an unpublished Ph.D Thesis, University of London.

Akande, A. T. (2002). Acquisition of Inflectional Morphemes by Nigeria Learners of English Language.Nordic Journal of African Studies, 11(2), 236-248.

Amana, D., \& Omale, S. A. (2015). Hypothesis of Inverse effect in NollywoodFils' crisis Resolution.International Journal of African Society Cultures and Tradition, 2(1), 10-17.

Asiyanbola, A. A. (2003). Sentence-Formation Needs of Yoruba-Speaking Senior Secondary School Pupils and Sentence inputs in their English Course books, an unpublished Ph.DThesis, ObafemiAwolowo University.

Burn, A., \& Parker, D. (2003). Tiger's Big Plan: Multimodality and the Moving Image (ed) Jewitt, C., \& Kress, C. Multimodal Literacy. New York: Peter Lang, 56-72.

Halliday, M. A. K., \&Matthiessen, C. M. IM. (2004). An Introduction to Functional Grammar. London: Arnold.

Halliday, M. A. K. (1978). Language as Social Semiotic, London: Arnold, 123.

Jewitt, C., \& Kress, C. (2003).Multimodal Literacy. New York: Peter Lang, 1-6.

Jewitt, C. (2009). An Introduction to Multimodality. C Jewitt(ed) The Routledge Handbook of Multimodal Analysis. London and New York: Routledge, 14-27.

Kress, G. R., \& van Leeuwen, T. (2001). Multimodal Discourse. London: Arnold, 1-6.

Lemke, C. (2002). Travels in Hypermodality.Visual Communication, 1(3), 229-325. http://dx.doi.org/10.1177/147035720200100303

Machin, D. (2010). Analysing Popular Music, Los Angeles: Sage Publications.,78-90.http://dx.doi.org/10.4135/9781446280027

Machin, D. (2009). Multimodality and Theories of the visual.in C, Jewitt(ed), RoutledgeHandbook of Multimodal 
Analysis. London and New York: Routledge, 181-190.

Matinec, R. (2005). A System for Image-text Relations in New (and old) media.Visual Communication, 4(3), 337-371. http://dx.doi.org/10.1177/1470357205055928

Morris, D. (2015). Preventing early reading failure in The Reading Teacher, A Journal of the InternationalLiteracy Association. Newark DE USA, 68(7), 501-519.

Nash, W.,\&Stancey, D. (1980). Creating Texts: An Introduction to the Study of Composition.London: Longman, 220-221.

O’Halloran, K. L. (2002). Classroom Discourse in Mathematics: A Semiotic Analysis. Linguistics and Education, 10(3), 359-388. http://dx.doi.org/10.1016/S0898-5898(99)00013-3

O’Halloran, K. L. (2008). Systemic Functional Multimodal Discourse Analysis (SF-MDA): Constructing Ideational Meaning Using Language and Visual Imagery. Visual Communication, 7(4), 443-475. http://dx.doi.org/10.1177/1470357208096210

O’Toole, M. (1994). The language of Displayed Art. London: Leicester University Press.

O'Toole, M. (2010). The language of Displayed Art ( $2^{\text {nd }}$ ed): London and New York: Routledge

Olagoke, D. O. (1975). An Error Analysis of Lagos University Students, an unpublished Ph.D Thesis, University of London.

Olateju, M. A., \&Oyebode, O. (2014).Introducing Multimodality.Ibadan: College Press andPublishers Limited., 14.

Olateju, M. A. (2006). Cohesion in ESL Classroom Written Texts, Nordic Journal of African Studies, 15(3), $314-331$.

Oluikpe, B. O. (1974). A Neglected Problem of English Language Education in Nigerian Primary and Secondary Schools, JNESA, 6(2), 28-38.

Snell, E. K., Hindman, A. H., \&Wasik, B. A. (2015). How Can Book Reading Close the Word Gap? Five Key Practices FromResearch The Reading Teacher; A Journal of the International Literacy Association. Newark DE USA, 68(7), 565.

Tomori, S. H. O. (1963). An investigation into the Standard of Written English of Final Year Pupils in Some Western Nigerian Primary Schools, an Unpublished M.A Thesis, University of London.

Toolan, M. ( 1996). Language in Literature- An introduction to Stylistics. London: Arnold., 136.

Unsworth, L., \& Cleirigh, C. (2009).Multimodality and Reading: The Construction of Meaning through Image-Text Interaction', in C. Jewitt (ed), The Routledge Handbook of Multimodal Research. London and New York: Routledge, 151-163.

Whitehurst, G., \&Lonigan, C. (2001) Emergent Literacy: Development from pre-readers to readers. S. Newman \& D. Dickinson (eds), Handbook of Early Literacy Research New York, NY: Guilford, 11-29.

Wright, W. (1975). Six Guns and Society, Berkeley, CA: University of California Press.

\section{$(\mathrm{cc}) \mathrm{BY}$}

This work is licensed under a Creative Commons Attribution 3.0 License. 